\title{
Expression of IL-1ß and implantation serine proteases is required for mouse blastocyst hatching
}

\author{
Madhulika Pathak¹, Venkatappa Vani ${ }^{1}$, Surendra Sharma² and Polani B Seshagiri ${ }^{1}$ \\ ${ }^{1}$ Department of Molecular Reproduction, Development and Genetics, Indian Institute of Science, Bangalore, India \\ and ${ }^{2}$ Department of Pediatrics, Women and Infants Hospital of Rhode Island, Brown University, Providence, Rhode \\ Island, USA
}

Correspondence should be addressed to P B Seshagiri; Email: polani@iisc.ac.in

\begin{abstract}
Mammalian blastocyst hatching is a critically indispensable process for successful implantation. One of the major challenges in IVF clinics is to achieve superior embryonic development with intrinsically potent hatching-competent blastocyst. However, the molecular regulation of hatching phenomenon is poorly understood. In this study, we examined the expression and function of one of

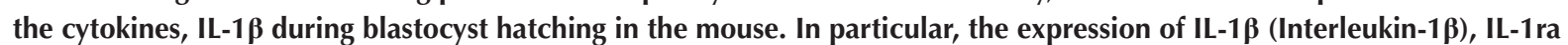
(Interleukin-1 receptor antagonist) and their functional receptor IL-1rt1 (Interleukin 1 receptor type-1) in morulae, zona intact- and hatched-blastocysts was studied. Supplementation of IL-1ß to cultured embryos accelerated blastocyst development with improved hatching (treated: $89.6 \pm 3.6 \%$ vs untreated: $65.4 \pm 4.1 \%$ ). When embryos were treated with IL-1 ra, blastocyst hatching was decreased (treated: $28.8 \pm 3.1 \%$ vs untreated: $67.5 \pm 3.8 \%$ ). Moreover, IL-1ß and IL-1 ra influenced the expression of hatching enzymes viz., implantation serine proteases (ISP1 and ISP2). While IL-1ß increased the embryonic mRNA expression of ISPs (Isp1: 2-4; Isp2: 9- to 11-fold), IL-1 ra decreased expression. The protein localization studies revealed increased nuclear presence

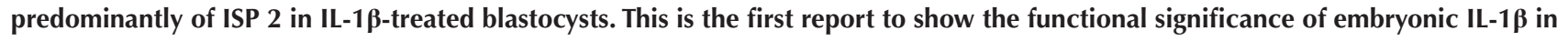
regulating hatching-associated proteases, particularly ISP2. These findings have implications in our understanding of molecular regulation of blastocyst hatching and implantation failure in other species including humans.

Reproduction (2021) 161 123-133
\end{abstract}

\section{Introduction}

Mammalian blastocyst hatching is an exemplary earlydevelopment phenomenon preceding the implantation event, both being pre-requisites for subsequent embryo viability and successful pregnancy (Seshagiri et al. 2009, 2016, Shafei et al. 2017). It is well documented that the biological viability of in vitro cultured embryos is inferior to those developing in vivo (Harlow \& Quinn 1982, Roth et al. 1994, Stokes et al. 2005, Chimote et al. 2013). Human infertility clinics perform assisted hatching techniques in a few indications, in order to achieve improved implantation rates (Ghannadi et al. 2011, Li et al. 2016). Such approaches pose unintended adverse effects on embryonic viability, hatching failure, monozygotic twinning and possibly mutations in the embryonic genome (Hammadeh et al. 2011, Huang et al. 2019, Lu et al. 2019). Therefore, it is essential to understand the biology of development of hatching-competent blastocysts and to determine the causes of hatching failure. Unlike extensive research on implantation biology (Singh et al. 2011), studies on the molecular regulation of blastocyst hatching biology per se are scarce in most species studied (Seshagiri et al. 2009, 2016). Among animal models studied so far, the mouse has been a main-stay to study early peri-implantation development (Taft 2008).

Blastocysts of the mouse, similar to human, exhibit hatching behavior which includes expansion of blastocoel, its increased hydrostatic pressure, zona thinning and leading to rupture of the zona (Lin et al. 2001, Sathananthan et al. 2003, Leonavicius et al. 2018). These mechanical events, occurring during hatching, are believed to be accompanied by secretory zonalytic protease-factors (Perona \& Wassarman 1986, Seshagiri et al. 2009, 2016, Shafei et al. 2017). In the mouse, blastocyst-hatching enzymes such as (1) trypsinlike serine protease (Sawada et al. 1990) and (2) a set of serine proteases ISP1 and ISP2 are implicated in blastocyst hatching (O'Sullivan et al. 2001, 2002, Sharma et al. 2006). Interestingly, the ISP1, exclusively expressed in the mouse, is hypothesized to have neofunctionality as a hatching enabling enzyme (Sharma et al. 2006). Besides, in non-embryonic cells, the expression of serine-like proteases is reported to be regulated by IL-1 $\beta$ (Indalao et al. 2017). 
A plethora of implantation-associated molecules, such as steroid hormones, growth factors, cytokines, enzymes and transcription factors (Singh et al. 2011, Bulun 2017, Raheem 2018), have been extensively studied. Ironically, they have not been examined, with any details, in the context of blastocyst hatching in species studied (Pan et al. 2015, Shafei et al. 2017, Zhan et al. 2018). In mouse, embryonic expression of various cytokines was examined and their potential involvement in the regulation of development of preimplantation embryos has been reported (Gerwin et al. 1995, Krussel et al. 1998, Nakasato et al. 2004, Seshagiri et al. 2016, Robertson et al. 2018). Much of the functional data on cytokines and their signaling systems come from gene knockout studies (Stewart et al. 1992, Murphy et al. 2005, Uri-Belapolsky et al. 2014). However, observations made did not indicate any profound implantation-failure phenotypes and importantly, the hatching phenotype (Seymour et al. 1997), including an assessment of embryos during preimplantation development and whether or not mutant blastocysts were capable of hatching. Of relevance, in this context, are reports on the expression and involvement of interleukin-1 $\beta$ (IL-1 $\beta$ ), interleukin-1 receptor antagonist (IL-1 ra) and interleukin-1 receptor type I (IL-1RtI) during the peri-hatching development (Kita et al. 1994, Kruessel et al. 1997, 1998, Correia-Álvarez et al. 2015). In humans, both the embryo and the endometrium express IL- $1 \beta$ and its increasing concentration is associated with successful implantation. In this regard, IL-1 $\beta$ is thought to be a potent embryo biomarker for successful implantation (Sequeira et al. 2015, Salama et al. 2020). Moreover, the embryonic expression of IL-1 ra cytokine, the natural antagonist of IL-1 $\beta$, has been shown to be associated with developmentally arrested embryos (Kruessel et al. 1997, Simón et al. 1998).

However, the role of IL-1 $\beta$ in blastocyst development and hatching remains poorly studied. In the mouse, there are contradictory reports on the functional significance of IL-1 $\beta$ in the implantation process (Abbondanzo et al. 1996, Simón et al. 1998). In the context of pre-implantation development, reports on the involvement of IL-1 $\beta$ are very scarce and inconclusive (Schneider et al. 1989, Tartakovsky \& Ben-Yair 1991). For example, the administration of IL-1 $\beta$ to mouse promoted the advanced development of morulae (Tartakovsky \& Ben-Yair 1991). In contrast, interleukins (IL-1 $\beta$ ) did not promote the development of cultured mouse embryos to blastocysts (Schneider et al. 1989). These findings provide a compelling reason to investigate the potential involvement of IL-1 $\beta$ in blastocyst development and hatching. Here, we present data on the embryonic expression and function of both IL-1 $\beta$ and IL-1ra in the context of blastocyst development and hatching in the mouse.

\section{Materials and methods}

\section{Animals}

Albino mice (CD1 or FVB/N strain) were used for the study. Animals were provided with proper light-dark cycle, temperature, humidity, food and water. Sexually mature females (6-8 weeks old) were observed for regular estrus cyclicity, assessed by vaginal gross-morphology. Healthy, regularly cycling females were selected as embryo donors. The Institutional Animal Ethics Committee approved procedures for animal handling and experimentation, in accordance with guidelines on the use of laboratory animals for research (INSA, New Delhi).

\section{Embryo recovery and culture}

Embryo donor female mice $(n=50)$ were super-ovulated with an i.p. injection of 5 IU Pregnant Mare Serum Gonadotropin (PMSG, Sigma or Folligon, MSD) on the day of estrus. This was followed, post-48 h, by HCG injection. Females were then kept with sexually mature healthy males for mating. In the evening of post-day 3 of mating, in vivo developed, compacting eight cells or morulae were collected by flushing the excised uterine horns with pre-equilibrated M-2 medium contained in a blunted hypodermic flushing needle; recovered embryos were cultured in vitro in 50 $\mu \mathrm{L}$ micro-drops of $\mathrm{M}-16$ medium (prepared freshly using embryo culture grade components from Sigma) in $35 \mathrm{~mm}$ dishes (Greiner) at $37^{\circ} \mathrm{C}$ in a humidified gas atmosphere of $5 \% \mathrm{CO}_{2}$ in air incubator (Hogan et al. 1986). Embryo culture drops were overlaid with $2.5 \mathrm{~mL}$ of pre-equilibrated embryotested silicone oil (Sigma). For each experiment, a group of 4-10 embryos were cultured in each treatment drop. Embryo development was monitored microscopically every $12 \mathrm{~h}$ for a total of 60-72 h for development and hatching. Embryos, sampled for expression analysis, were either frozen for RNA isolation or fixed in $4 \%$ paraformaldehyde (Sigma) for immunocytochemistry (ICC) analysis. For IL-1 $\beta$ or IL-1ra-treated embryos, samples collected were a pool of embryos from a single medium drop containing 4-10 embryos. Embryos were washed with PBS and were frozen $\left(-80^{\circ} \mathrm{C}\right)$ in $10 \mu \mathrm{L}$ of PBS.

\section{Supplementation of IL-1 $\beta$ and IL-1ra in embryo culture}

The influence of IL-1 $\beta$ (PMC0814; GIBCO, Thermoscientific) and IL-1ra (cyt-658; Prospec) were tested on blastocyst hatching. Working solutions with test compounds were prepared in M-16 medium. About 4-10 embryos per treatment were cultured in M-16, without or with the test compounds, for $60 \mathrm{~h}$ and a minimum of four replicate experiments were performed. For IL-1 $\beta$ and IL-1ra supplementation studies, a total of 15 and 10 females were used, respectively. A randomized distribution of an equal number of synchronously developed embryos from individual donors was adopted. All embryos were monitored for viability, gross-morphology, hatching rates and post-hatching trophoblast outgrowths. Total 
cell numbers of (hatched) blastocysts were monitored. Photomicrographic images were captured, using a CCD camera and Image Cell Sens software program (Mishra \& Seshagiri 1998, Sireesha et al. 2008). For dose-dependent studies, doses were selected based on published reports (Paula-lopes et al. 1998) and as recommended by the safety data sheet/product information from the company. Besides, experiments were also performed for dose-determination, which was selected for subsequent experiments.

\section{Embryo mRNA isolation and cDNA synthesis}

Using saved frozen embryos (10-20, pooled), direct polyA ${ }^{+}$ mRNA isolation was performed using Dynabead mRNA DIRECT Kit (61011, Invitrogen/Life Technologies; as per provided protocol). This relied on base-pairing between poly A residues at 3' end of mRNA and the oligo dT25 residues that were covalently coupled to the surface of Dynabeads. The RNA was then subjected to cDNA synthesis in $20 \mu \mathrm{L}$ reaction mixture, using Verso cDNA synthesis kit (AB-1453/A, Thermoscientific; as per the provided protocol). The synthesized cDNA was then subjected to gene amplification.

\section{Quantification of embryonic gene expression using $q P C R$}

The embryonic cDNA used per reaction was a half embryo equivalent (i.e. if cDNA from a pool of 10 embryos was reconstituted in $20 \mu \mathrm{L}$ solution, then, $1 \mu \mathrm{L}$ is considered as half embryo equivalent). The reaction was set in duplicates for each sample. Three biological replicates were performed with each one constituting a pool of 10-20 embryos of each stage (one sample) for stage-dependent expression and, for IL-1 $\beta$ or IL-1 ra-treated embryos, 5-10 embryos per replicate were used for analysis. The qPCR conditions used for all primers were $95^{\circ} \mathrm{C}$ for $2 \mathrm{~min}$ for initial denaturation, followed by 40 repetitive cycles consisted of steps: (1) $95^{\circ} \mathrm{C}$ for $15 \mathrm{~s}$ for subsequent denaturation, (2) annealing step of $58^{\circ} \mathrm{C}$ for $60 \mathrm{~s}$ and final step and $(3) 72^{\circ} \mathrm{C}$ for $30 \mathrm{~s}$ for extension. This was followed by melting curve analysis at $95^{\circ} \mathrm{C}$ for $15 \mathrm{~s}$, followed by $60^{\circ} \mathrm{C}$ for $15 \mathrm{~s}$ and $95^{\circ} \mathrm{C}$ for $15 \mathrm{~s}$. The analysis was performed using Step One Plus Real Time PCR (Applied Biosystem) system using Syber Green PCR Master Mix (Cat. No. AB-1053/A, Thermoscientific). The result was analyzed using Stepone software 2.2.2 and Ct values were calculated from the amplification plot. The actin gene normalization was performed for each sample in each assay to minimize the sample to sample and assay to assay variations. The expression values were assessed by calculating normalized$\Delta \mathrm{Ct}$ Value (Ct (test gene) - Ct (Actb gene)) and plotting $2^{-\Delta \mathrm{Ct}}$ values to show relative expression during different embryonic stages. In order to calculate fold change of IL-1 $\beta$ / IL-1 ra-treated embryos with respect to the control untreated embryo samples, the calibrated $\Delta \Delta$ Ct value was calculated by subtracting normalized $\mathrm{Ct}$ values of the two genes; $\Delta \mathrm{Ct}$ (test, e.g. gene expression in treated embryos) $-\Delta \mathrm{Ct}$ (calibrator, e.g. gene expression in untreated embryo samples). The $2^{-\Delta \Delta \mathrm{Ct}}$ was plotted as fold change. The 'No Template Controls' were included in all experiments.
The nucleotides sequences of primers used were:

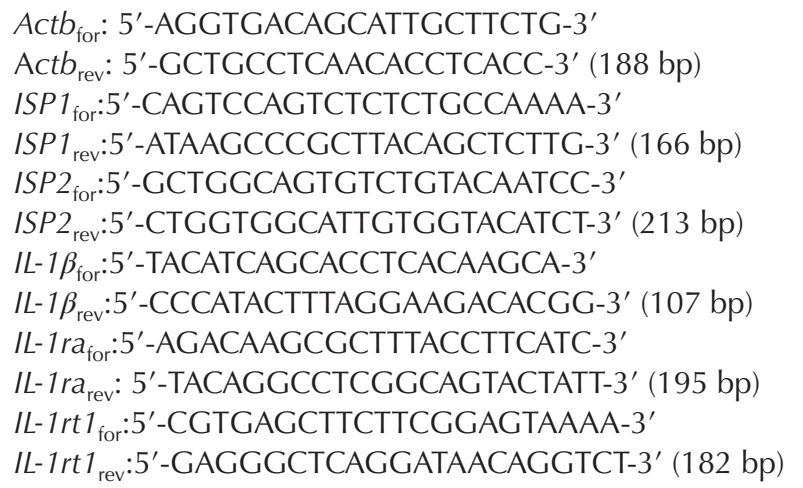

\section{Whole-mount immunocytochemistry (ICC) and quantification}

Embryos, fixed in PFA (4\% in PBS, Sigma), were rinsed in PBSPVA and then permeabilized with $0.2 \%$ Triton X-100 for 15 min and blocked in $0.3 \%$ BSA for $2 \mathrm{~h}$ at room temperature. Embryos were rinsed again in PBS-PVA (Sigma) and then incubated with the corresponding anti-mouse primary antibody; polyclonal goat IgG IL-1 $\beta$ (AB-401-NA, R\&D systems), polyclonal goat IgG IL-1rt1 (ITAB11621, Immunotag), rabbit polyclonal IgG IL-1 ra (32594, Signalling Antibody), Polyclonal Rat IgG ISP 2 (MBS1495206, Mybiosource), for overnight at $4^{\circ} \mathrm{C}$. The dilution of the primary antibody used was 1:200 in blocking solution except for IL-1 ra, which was used at 1:50 dilution. Control embryos were incubated in blocking solution without primary antibody. After washing in PBS-PVA, embryos were subjected to incubation with secondary antibody, that is, polyclonal donkey IgG alexa fluor 633/alexa 594 conjugated anti-goat IgG (Invitrogen) or anti-rabbit IgG-FITC conjugated or anti-rat alexa fluor 568 (Invitrogen/Life Technologies), at dilution of 1:500 for $45 \mathrm{~min}$ at room temperature. For nuclear staining, embryos were stained with DAPI $(10 \mu \mathrm{g} /$ $\mathrm{mL}$, Sigma) for $15 \mathrm{~min}$ at room temperature. Embryos were then washed a couple of times in PBS-PVA and then mounted using prolonged gold anti-fade mountant (Invitrogen) on the $0.2 \mathrm{~mm}$ coverslips, later inverted on concavity glass slides. The slides were imaged using Zeiss LSM 510/LSM 880 confocal laser scanning microscope (Carl Zeiss) using Zen 2.1 software. For immuno quantification, a total of 3-4 embryos of each stage was analyzed for embryonic stage-dependent protein expression level analysis. For IL-1 $\beta /$ IL-1 ra supplementation experiment, a total of 5-8 embryos was analyzed from each treatment group.

\section{Zona thickness measurement studies, viability assay, differential cells (trophectoderm (TE)-inner cell mass (ICM) determination and cell attachment assay}

Images of cultured zona-intact embryos, at different stages, were captured and subjected to zona thickness measurement using the software; the digital scale provided in the software was calibrated using a manual micrometer $(10 \mu \mathrm{m})$ scale. The thickness of the zona was measured using arbitrary line 
drawn, spanning their width of the translucent zona layer. Measurements were made at four different quadrants of the zona, at two or more magnifications; their mean values were taken. For partially hatched embryos, measurements were carried out at three different points and the mean value was calculated for each embryo. The viability of embryos was assessed using $0.5 \%$ trypan blue dye exclusion test. Allocation of cells to TE and ICM of cultured blastocysts was determined by ICM-cell-specific staining using OCT-4 (Santa Cruz Biotechnology) antibody, followed by nuclear staining using DAPI (10 $\mu \mathrm{g} / \mathrm{mL}$, Sigma). Blastocyst attachment and TB outgrowth cultures and their morphometric analysis were performed, as described elsewhere (Mishra \& Seshagiri 1998). The TB outgrowth was assessed under an inverted microscope (IMT-2; Olympus Co Ltd), using phase-contrast objectives. Morphometric measurements of TB outgrowth were made using an image analysis software provided by Cell Sens.

\section{Statistical analysis}

Mean values in all experiments were calculated from the total number of embryos cultured during a particular treatment. To control between-animal variations, a block design was used. For this, freshly recovered embryos from each donor female were distributed randomly and in similar numbers among all treatments and this constituted one replicate experiment. Moreover, all replicate experiments were performed under identical experimental conditions. This design considerably strengthened the statistical analysis of data. Hence, the statistics were based on the number of biological replicates, that is, a different set of experiments that were performed (independent of the number of donors used). A minimum of 4-10 replicate experiments (from minimum of three different animals) were performed. To assess the statistical significance of treatment effects, one-way ANOVA/Student's t-test/two-way ANOVA, followed by Bonferronni's post hoc, tests were performed to obtain $P$-value (Graph Pad Prism Software Version-4).

\section{Results \\ Embryonic expression of IL-1 $\beta$, IL-1 ra and IL-1rt1 during peri-hatching development}

We first analyzed the embryonic development stagedependent expression patterns of $I L-1 \beta$, its natural antagonist IL-1ra, and its functional receptor IL-1rt1 (Fig. 1). This was performed with freshly recovered morulae, expanded zona-intact blastocysts and hatched blastocysts. The analysis of mRNA levels of the above revealed a stage-dependent pattern with an increase in the expression of $I L-1 \beta$ (Fig. $1 \mathrm{~A}-\mathrm{i}$ ); however; the differences in expression were not statistically significant. In contrast, a statistically significant decrease in the expression of IL-1 ra was observed as the development of embryos progressed (Fig. 1A-ii, $P<0.05$ ). Similar levels of expression of IL-rt1 were observed in three stages of embryo development (Fig. 1A-iii). When their protein expression and localization studies were performed, it was observed that the IL-1 $\beta$ and IL-1ra were uniformly localized to the cytoplasm of all TE and ICM cells, whereas IL-1rt1 showed membrane-associated localization (Fig. 1B). The protein quantification (mean fluorescent intensity) of ICC data corroborated with the observed changes in mRNA levels (Fig. 1C).

\section{Influence of IL-1及 or IL-1ra on blastocyst hatching}

To investigate the functional role of IL-1 $\beta$ during blastocyst hatching, supplementation of IL-1 $\beta$ or its antagonist (IL-1ra) in the M-16 medium was made during independent embryo culture experiments. The cultured embryos developed to expanded blastocysts by $24 \mathrm{~h}$ (Fig. 2A-i, A-iii, A-v) and eventually, they hatched by $48 \mathrm{~h}$ (Fig. 2A-ii, A-iv, A-vi). The supplementation of IL-1 $\beta$ led to enhanced blastocyst hatching rate in a dosedependent manner. The observed increases in hatching percentages in the presence of IL-1 $\beta(1 \mathrm{ng} / \mathrm{mL}$ or $2 \mathrm{ng} /$ $\mathrm{mL}$ ) were $76.3 \pm 1.3 \%$ (not significant) or $88.8 \pm 6.6 \%$ $(P<0.01)$, when compared to untreated control $(58.7 \pm 5.9 \%$; Fig. $2 \mathrm{~B}-\mathrm{i})$. Additional experiments were also performed with only effective dose of $2 \mathrm{ng} / \mathrm{mL}$ of IL-1 $\beta$. It was observed that the supplementation of IL-1 $\beta$ yielded significantly improved hatching percentages, that is, $89.6 \pm 3.6 \%$, when compared to untreated control blastocysts $(65.4 \pm 4.1 \%$; Fig. $2 \mathrm{~B}-\mathrm{ii}, P<0.001)$.

Two independent set of experiments were performed to examine the influence of varying concentrations of IL-1 ra on blastocyst hatching. In the first set, embryos were cultured in the presence of 0.5 or $1 \mathrm{ng} / \mathrm{mL}$ concentration of IL-1 ra (Fig. 2C-i) and percentages of hatched blastocysts observed, respectively, were $33.3 \pm 8.3$ or $8.3 \pm 8.3$ $(P<0.05)$; the percentage of hatched blastocysts in the untreated control was $66.6 \pm 6.6$ (Fig. 2A-vi, C-i). To mitigate the possible observed embryo-toxicity of IL-1 ra, subsequent experiments were performed using a lower concentration of IL-1 ra, that is, $0.2 \mathrm{ng} / \mathrm{mL}$. In this set of experiment, while $67.5 \pm 3.8 \%$ of embryos hatched $(60$ h) in the untreated control, IL-1 ra-treated $(0.2 \mathrm{ng} / \mathrm{mL})$ embryos showed reduced hatching percentage (28.8 \pm 3.7 , $P<0.01$; Fig. 2C-ii). When we analyzed the effect of IL-1 $\beta$ on cellular viability and differential cell counts of TE and ICM of cultured blastocysts and, the trophoblasts outgrowth capability of hatched blastocysts, we observed no significant effect on these parameters whether or not embryos were treated with the IL-1 $\beta$ (data not shown).

\section{Influence of IL-1及 on time-kinetic of hatching and zona thinning}

To elucidate the hastening effect of IL-1 $\beta$ on blastocyst hatching, we performed the time kinetics of blastocyst hatching (Fig. $3 \mathrm{~A}$ and $\mathrm{B}$ ). The hatching rate trajectory was dose-dependent (Fig. 3A) and it was more pronounced with embryos treated with $2 \mathrm{ng} / \mathrm{mL}$ of IL-1 $\beta$ (Fig. 3B). The percentage of blastocysts hatched in the IL-1 $\beta$-treated 
A

(i)

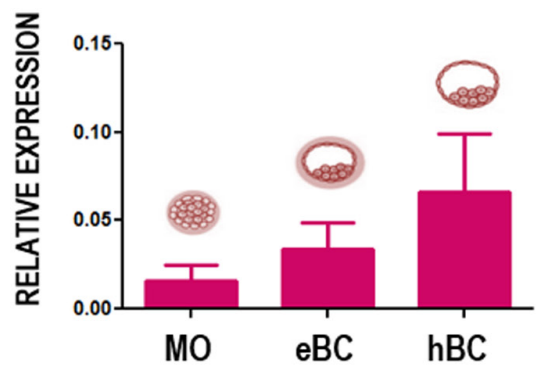

B
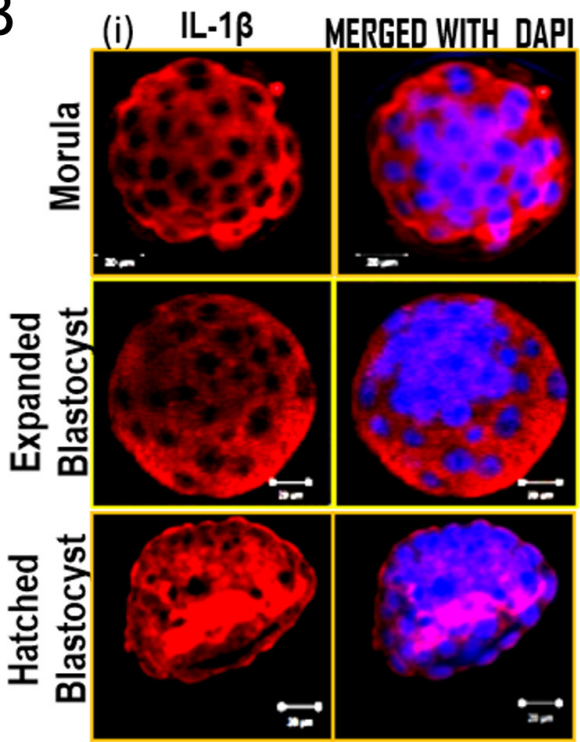

C

IL-1 $\beta$

(i)

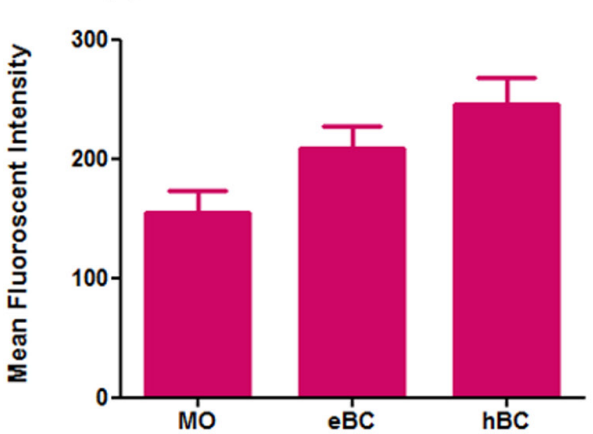

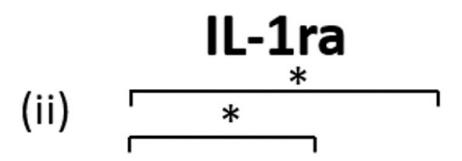
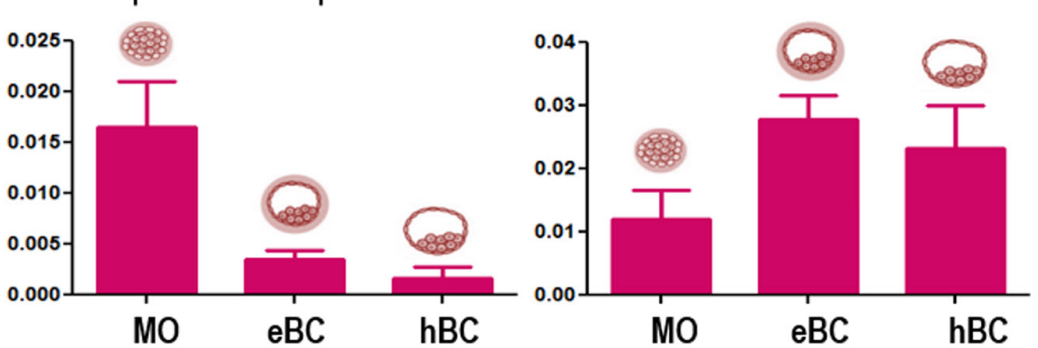

(ii) IL-1ra MERGED WITH DAPI
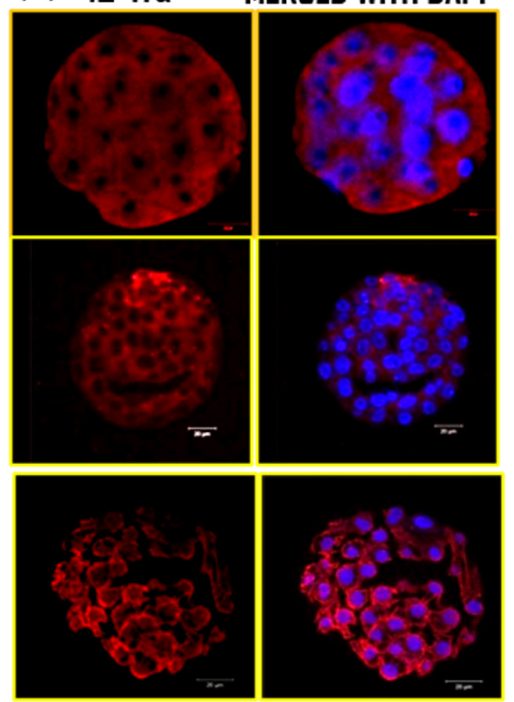

IL-1ra
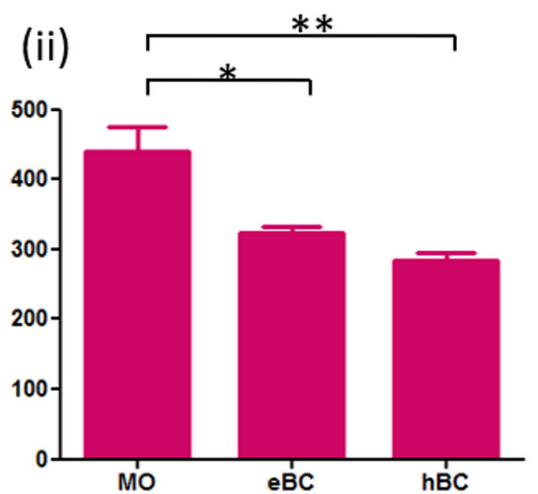

IL-1rt1

(iii)

(iii) IL-1rt1 MERGED WITH DAPI

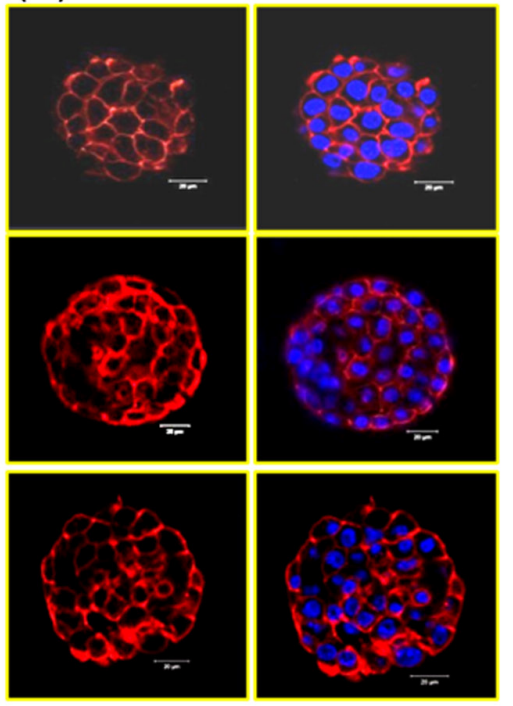

IL-1rt1

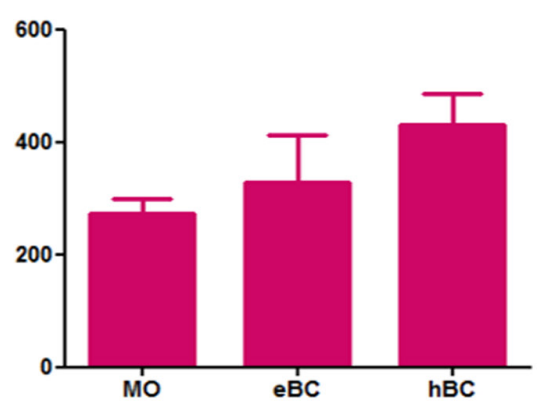

Figure 1 Embryonic expression of $I L-1 \beta, I L-1 r a$ and $I L-1 r t 1$ during peri-hatching stages of embryo development. Panel A depicts the quantification of embryonic transcript levels of IL-1 $\beta$ (A-i), IL-1 ra (A-ii) and IL-1rt1 (A-iii), in peri-hatching embryonic stages. Panel B depicts immunostained images of morula, blastocyst and hatched blastocyst. Immunolocalization of three proteins are shown, namely embryonic IL-1 $\beta$ (B-i), IL-1 ra (B-ii) and IL-1 rt1 (B-iii). Right panels in each set show merged images of immunostainings with DAPI, with Scale bar: $20 \mu \mathrm{m}$. Panel C depicts the quantification of fluorescent intensity levels of IL-1 $\beta$ (C-i), IL-1 ra (C-ii) and IL-1 rt1 (C-iii), in peri-hatching embryonic stages. Values represent mean \pm s.E.M. for minimum of three biological replicates. Statistical difference was determined using one-way ANOVA, subjected to postBonferroni's test. ${ }^{*} P<0.05,{ }^{* *} P<0.01$. MO, morulae; eBC, expanded blastocysts; hBC, hatched blastocysts. 
A
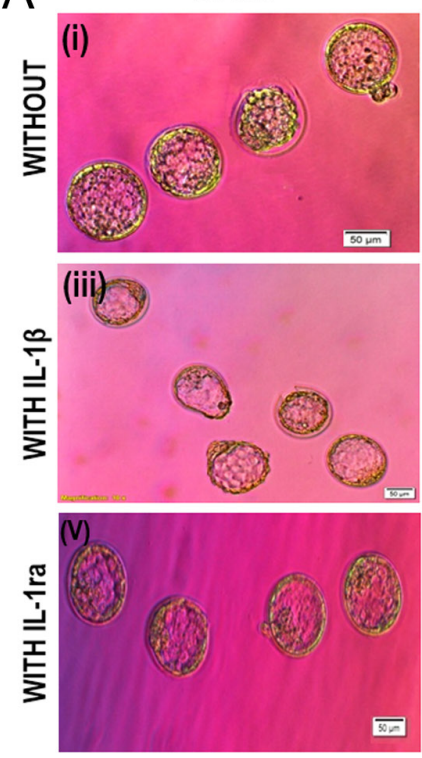

$48 \mathrm{hrs}$
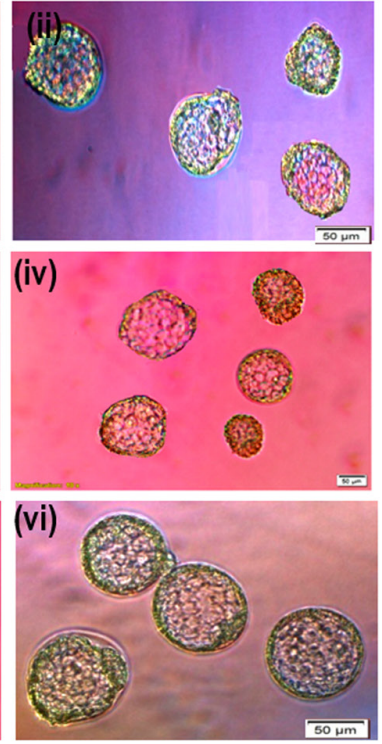

B

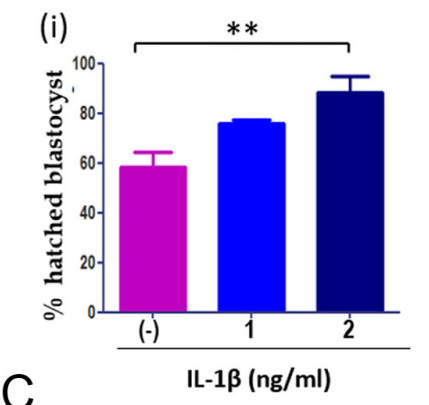

(ii)

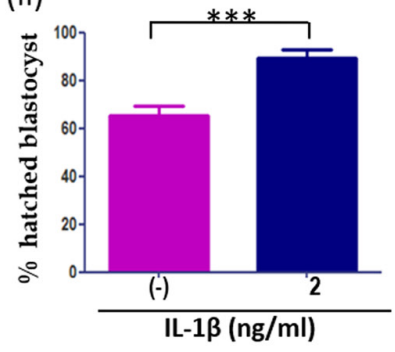

(ii)
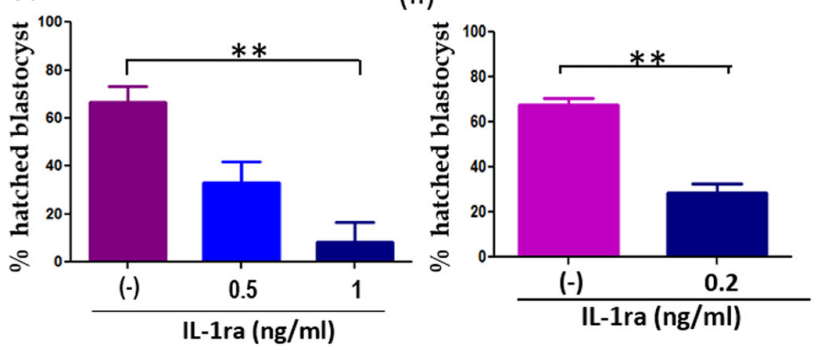

Figure 2 Effect of IL-1 $\beta /$ IL-1 ra treatment on blastocyst hatching. Panel A depicts representative morphology of development of freshly recovered morulae to blastocysts in the untreated group (A-i, A-ii) vs the IL-1 $\beta$-treated group ( $2 \mathrm{ng} / \mathrm{mL}$ ) (A-iii, A-iv) and IL-1 ra-treated group $(0.2 \mathrm{ng} / \mathrm{mL}$ ) (A-v, A-vi). Panel B depicts the graph showing the total percentage of hatched blastocysts, observed under untreated vs IL-1 $\beta$-treated group. Panel $\mathrm{C}$ shows the bar graph depicting the total percentage of hatched blastocysts, observed for the untreated vs IL-1 ra-treated embryos at a different dosage. Photographs were captured with Nomarski optics. Magnification: 10× and Scale bar: $20 \mu \mathrm{m}$. Values in the graph represent mean \pm S.E.M. for a minimum of four biological replicate experiments. Statistical difference was determined using one-way ANOVA, subjected to post-Bonferonni's test. ${ }^{* *} P<0.01,{ }^{* * *} P<0.001$.

group, at the $24 \mathrm{~h}$ time point, was $24.3 \pm 4.7 \%$ when none was observed in the untreated control group (Fig. 3B, $P<0.01)$. Blastocysts supplemented with IL-1 $\beta$ were invariably associated with hastened hatching behavior when compared to untreated control embryos.

As the embryo culture progressed, a relatively nonsignificant and similar zona thickness $(3.7 \pm 0.7 \mu \mathrm{m})$ was observed in the IL-1 $\beta$-treated embryos or the control embryos, post- $48 \mathrm{~h}$ of culture (Fig. $3 \mathrm{C}$ ). The zona thickness measurements for partly hatched embryos were made separately at $48 \mathrm{hr}$ (Fig. 3D). The zona thickness for the IL-1 $\beta$-treated, partly hatched embryos was $2.2 \pm 0.1 \mu \mathrm{m}$, when compared to the untreated control embryos $(3.3 \pm 0.4 \mu \mathrm{m}$; Fig. 3D). The average thickness of ruptured zona, left behind in the untreated embryos, was similar to IL-1 $\beta$-treated embryos $(3.7 \pm 0.5$ $\mu \mathrm{m}$ vs $3.4 \pm 0.4 \mu \mathrm{m}$ ) at $48 \mathrm{~h}$ (Fig. 3D). The retention of elasticity of the ruptured zona was responsible for the observed increasing patterns in the zona thickness posthatching. Hence, the effect of IL-1 $\beta$ on zona-thinning was non-significant.

\section{ISPS mRNA level in IL-1//IL-1 ra supplemented embryos}

The effect of IL-1 $\beta$ or IL-1ra on the expression of hatching associated proteases, that is, Isp 1 and Isp2 was examined (Fig. 4). Embryos cultured without or with IL-1 $\beta$ were used for analysis. The embryonic transcript levels of both Isp 1 and Isp2 significantly increased in the IL-1 $\beta$-treated zona-intact blastocysts, that is, $3.5 \pm 0.5$ fold for Isp1 $(P<0.05)$ and $11.7 \pm 2.6$-fold for Isp2 (Fig. $4 \mathrm{~A}-\mathrm{i}, P<0.01)$. With the IL-1 $\beta$-treated embryos, at the hatched stage, a statistically significant increase was observed in the transcript level of Isp2 (9.1 \pm 1.4 -fold, $P<0.05)$ than that $(2.8 \pm 1.1$-fold) of $I s p 1$ (Fig. 4 A-ii).

Similarly, the expressions of Isp1 and Isp2 were quantitatively analyzed for embryos cultured in the presence and absence of IL-1 ra $(0.2 \mathrm{ng} / \mathrm{mL})$. The transcript levels of both, Isp 1 and Isp2 decreased in the IL-1 ra-treated blastocysts. The reduction in the expression level observed for Isp1 in IL-1ra-treated blastocyst was by $73.2 \pm 3 \%(0.26 \pm 0.03$-fold, $P<0.05$; Fig. $4 \mathrm{~B})$ as opposed to the untreated embryos. For Isp2 also, there was a statistically significant decrease in the expression level by $82.3 \pm 11 \%(0.17 \pm 0.11$-fold, $P<0.01$; Fig. $4 \mathrm{~B})$ in the IL-1 ra-treated zona-intact blastocysts (Fig. 4B), when compared with the untreated control embryos. Because, the numbers of embryos hatched in the presence of IL-1 ra were too low, the mRNA expression analysis was not performed for the hatched blastocyst stage.

\section{ISP2 protein levels in IL-1/ or IL-1ra supplemented embryos}

To analyze protein levels of proteases, we focused on transcriptionally more abundant ISP2. Cultured 

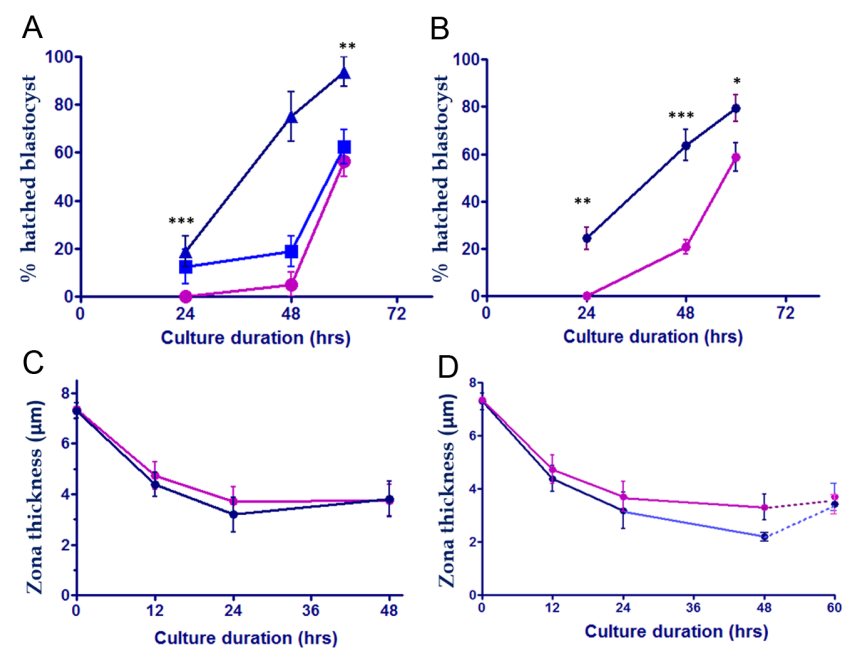

Figure 3 Time kinetics of development of blastocysts in the presence and absence of IL-1 $\beta$. (A) Represents \% hatched blastocysts observed at different time points for IL-1 $\beta$-treated $(1 \mathrm{ng} / \mathrm{mL}$, blue squares or 2 $\mathrm{ng} / \mathrm{mL}$, dark blue triangles) embryos, compared to untreated control (pink circles). (B) Represents \% hatched blastocysts observed at different time points for optimized concentration of $2 \mathrm{ng} / \mathrm{mL}$ (dark blue circles) as compared to untreated control (pink circles). (C) Represents the influence of IL-1 $\beta$ on zona thickness of untreated (pink circles) and $2 \mathrm{ng} / \mathrm{mL}$ IL-1 $\beta$-treated (blue circles) zona-intact blastocysts, till $48 \mathrm{~h}$. (D) Depicts the zona thickness of untreated (pink circles) and IL-1 $\beta$-treated (dark blue circles) zona-intact blastocysts, till $24 \mathrm{~h}$ and partly hatched blastocyst at $48 \mathrm{~h}$. Dotted lines (...) in both line-graphs represent ruptured zona. Values in the graph represent mean \pm S.E.M. for a minimum of four biological replicate experiments. Statistical difference was determined using one-way ANOVA from four replicate experiments for (A) and eight replicate experiments for (B). ${ }^{*} P<0.05,{ }^{* *} P<0.01,{ }^{* * *} P<0.001$.

blastocysts were subjected to protein localization studies. Localization of ISP2 was observed in the TE and ICM (predominantly nuclear) cells in the IL-1 $\beta$-treated as well as untreated embryos (Fig. 5A and C). Quantitative analysis of immunostained zona-intact blastocysts for ISP2 showed a differential level of fluorescent intensity among IL-1 $\beta$-treated and untreated embryos (Fig. 5B and D). Mean immunofluorescence intensity quantification showed an increased level of ISP2, following the treatment of IL-1 $\beta$. The mean intensity for ISP2 immunofluorescence was $4672 \pm 177.4$ in the IL-1 $\beta$-treated blastocyst, whereas its level was $3832 \pm 70.20$ in the untreated control embryos (Fig. 5B, $P<0.05$ ). Protein localization for ISP2 was also performed in fully hatched embryos (Fig. 5C). Quantitative analysis showed increased levels of ISP2 protease following treatment with IL-1 $\beta$ (Fig. 5D). The mean intensity for ISP2 immunofluorescence in hatched blastocyst was $4511 \pm 136.2$ in the IL-1 $\beta$-treated embryos, whereas its level was $3700 \pm 90.17$ in the untreated control embryos (Fig. 5D, $P<0.01$ ). The observed increase in the ISP2 protein corroborated with the increase in its mRNA expression level.
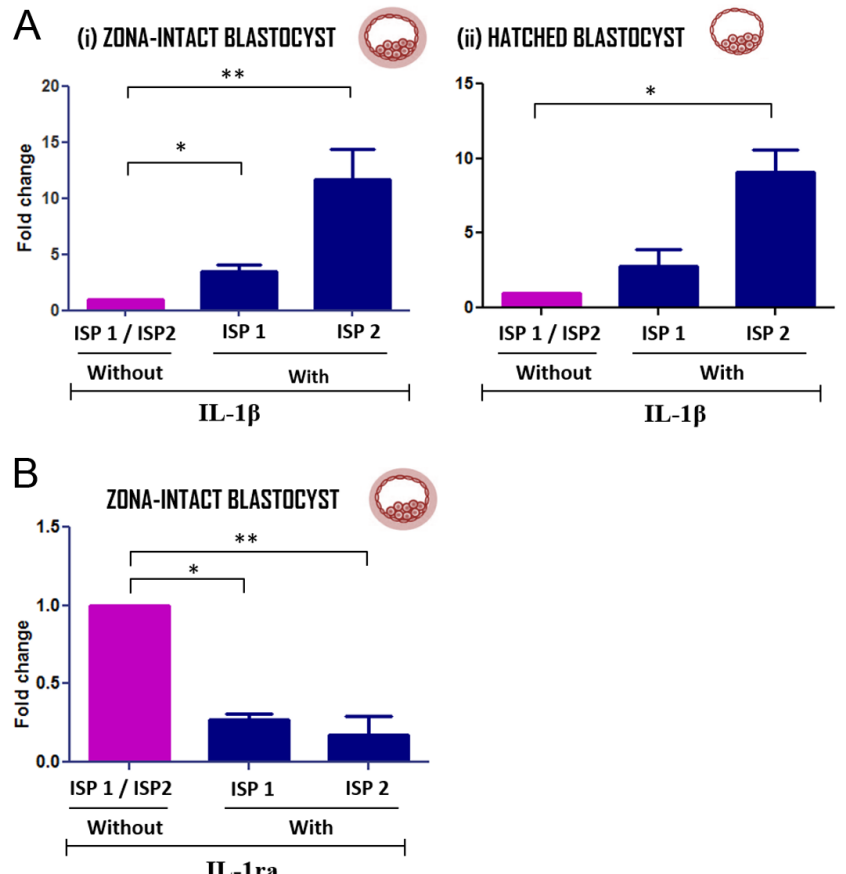

Figure 4 Influence of IL-1 $\beta$ or IL-1 ra on mRNA level of ISPs in cultured blastocysts. Panel A-i depicts mRNA levels of Isp1 and Isp2 under IL-1 $\beta$-treated $(2 \mathrm{ng} / \mathrm{mL}$ ) vs untreated conditions in zona-intact blastocysts. Panel A-ii depicts mRNA levels of Isp1 and Isp2 under IL-1 $\beta$-treated vs untreated conditions in hatched blastocysts. Panels B depicts quantification of transcript levels of Isp1 and Isp2 under IL-1 ra-treated $(0.2 \mathrm{ng} / \mathrm{mL})$ and untreated conditions in zona-intact blastocysts. Values represent mean \pm S.E.M. of three biological replicate experiments. Statistical analysis was carried using two-way ANOVA subjected to post-Bonferonni's test. ${ }^{* *} P<0.01 * P<0.05$.

The colocalization studies for both the IL- $1 \beta$ and ISP2 were performed under IL-1 ra supplemented conditions. There was a significant reduction in the level of both proteins, IL-1 $\beta$ and ISP2 (Fig. 6A and B). Quantitative analysis of immunostained zona-intact blastocysts, for IL-1 $\beta$ and ISP2 showed a differential level of fluorescent intensity in IL-1 ra-treated embryos when compared to the untreated ones (Fig. 6B, $P<0.05$ ). Mean intensity for IL-1 $\beta$ fluorescence was $3304 \pm 1528$ in treated embryos, whereas its level was $3931 \pm 75.2$ in the untreated control embryos (Fig. 6B). Mean intensity for ISP2 immunofluorescence was $3917 \pm 152.8$ in the IL-1 ratreated embryos, whereas its level was $4124 \pm 292.8$ in the untreated embryos (Fig. 6B, $P<0.05$ ).

\section{Discussion}

This study shows, for the first time, the involvement of IL-1 $\beta$ in the development-hatching of blastocysts and in modulating the hatching-associated proteases, that is, ISP 1 and ISP 2 in the mouse. Earlier, the role of IL-1 $\beta$ during embryo implantation and in maintaining viable pregnancy was reported in the mouse (Sequeira et al. 2015, Salama et al. 2020) as well as in the human 

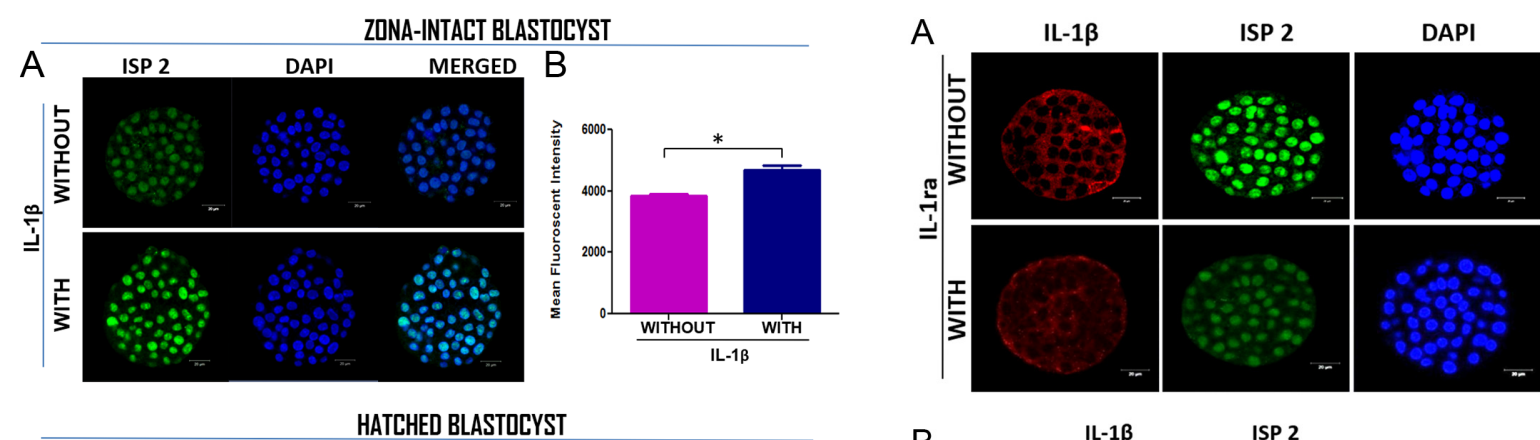

MERGED
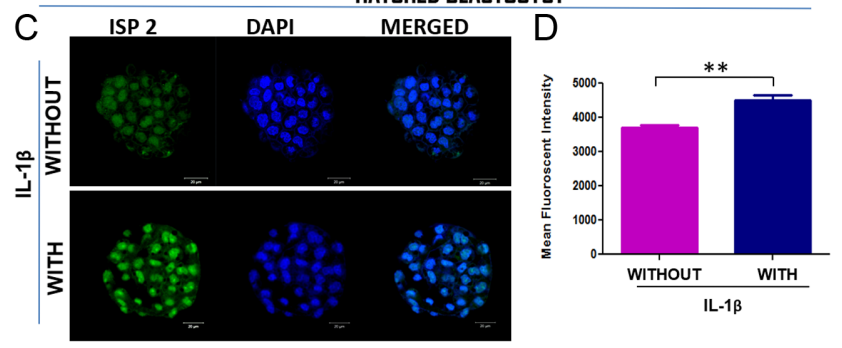

B

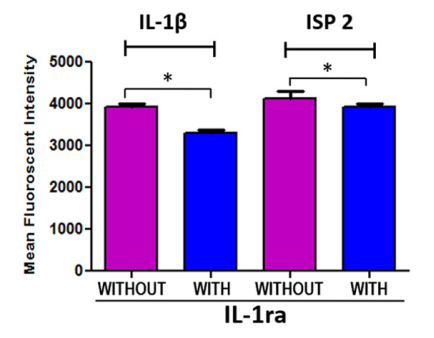

Figure 6 Influence of IL-1 ra on the ISP2 protein localization.

Panel A depicts the immuncolocalization of ISP 2 along with IL-1 $\beta$ in the absence and presence of IL-1 ra $(0.2 \mathrm{ng} / \mathrm{mL})$. Scale bar: $20 \mu \mathrm{m}$. Graph B denotes protein quantification (in arbitrary units) of IL-1 $\beta$ and ISP 2 in the presence or absence of IL-1 ra $(0.2 \mathrm{ng} / \mathrm{mL})$. Values represent mean \pm S.E.M. of four biological replicate experiments. Statistical analysis was carried using two-way ANOVA subjected to post-Bonferonni's test. ${ }^{*} P<0.05$.

blastocysts and hatched blastocysts. Interestingly, the ISP 2 protein level was higher in the IL-1 $\beta$-treated blastocysts and lower in IL-1 ra-treated blastocysts. Moreover, the IL-1 $\beta$-inducing effect of the protease could be countered by its natural antagonist IL-1ra. Thus, indicating a direct regulatory effect of IL-1 $\beta$ on the expression of hatchingassociated proteases. This particular observation on the involvement of the IL-1 $\beta$ - IL-1ra 'cytokine-set' in blastocyst hatching phenomenon in the mouse is a new finding and it is being reported for the first time. Previously, only a qualitative expression of $I L-1 \mathrm{ra}$ in individual blastomeres was reported (Kruessel et al. 1997). Our observation is the first to report the successful demonstration on the quantitative expression of IL-1ra in peri-hatching blastocyst stages and, importantly, we have observed a negative effect of IL-1 ra on the development and hatching of blastocysts. Of relevance here, is an earlier finding which showed that human embryos expressing IL-1 ra failed to develop into blastocysts (Kruessel et al. 1998). Besides, because IL-1 ra inhibits IL-1 $\beta$ signaling, it consequently leads to diminished gene expression of other IL-1 $\beta$-mediated expression of developmentally important genes (Simon et al. 1998). From the foregoing, we conclude that, by the virtue of IL-1ra inhibiting embryo-trophic activity of embryonically expressed IL-1 $\beta$, either directly or by diminishing the expression of IL-1 $\beta$ as well as ISPs, the IL-1 $\beta$ - IL-1 ra 'cytokine-set' is essential for blastocyst hatching.

We observed that the supplementation of IL-1 $\beta$ to cultured embryos increased blastocyst hatching 
percentage, accompanied by accelerated hatching by $24 \mathrm{~h}$. This hatching accelerating effect observed with the IL-1 $\beta$-supplemented embryos is very significant, since in vitro cultured mammalian embryos normally show a substantial delay in blastocyst development, compared to their in vivo counterparts (Harlow \& Quinn 1982, Roth et al. 1994, Stokes et al. 2005, Lange-Consiglio et al. 2020). Of relevance, here, is the recent report which showed an increased IL-1 $\beta$ in cultured human embryos and it is considered as an early predictor of a successful pregnancy (Salama et al. 2020). Taken together, it appears that IL-1 $\beta$ is important for improved development and hatching of blastocysts in humans and in other mammalian species as well. It is known that the behavior of hatching of mouse blastocysts is similar to humans and we did not observe any difference in the hatching process or zona thickness in the untreated or IL-1 $\beta$-treated embryos. This is in contrast to striking differences observed in the hamster species which show global dissolution of the zona during hatching (Seshagiri et al. 2009, 2016).

It will be intriguing to examine to what could be the mechanistic reasons for the observed effects of and IL-1 $\beta$ and IL-1 ra 'cytokine-pair' in regulating blastocyst hatching. It requires a detailed examination and it is beyond the scope of this study. However, based on earlier published reports with regard to the mechanistic involvement of signaling components, it is tempting to speculate that IL-1 $\beta$ could manifest its effect by activating JNK, MAPK and NF-KB in the blastocyst during hatching by virtue of these molecules being involved in survival, proliferation and inflammation (Lindroos et al. 1998, Lin et al. 2009, Weber et al. 2010). In this context, we earlier showed that, in hamsters, NF- $\mathrm{kB}$ and COX-1 act as potent positive regulators of hatching-associated zonalytic proteases (Sen Roy \& Seshagiri 2013, 2016). Drawing parallels with this, we, therefore, hypothesize that IL-1 $\beta$ could, in part, enhance the expression of hatching-associated proteases (ISPs), by activating the PGE2 pathway and the NF- $\mathrm{\kappa B}$ transcription signaling system (Schmitz et al. 2003, Weber et al. 2010), thereby enabling blastocyst hatching in the mouse.

In conclusion, our study successfully demonstrates that the IL-1 $\beta$ and IL-1ra 'cytokine-pair' modulates the hatching of mouse blastocysts via the regulation of expression of hatching-associated proteases, ISP 1 and ISP 2. The blastocyst development-hatching enhancing and accelerating effect of the IL-1 $\beta$ strongly indicates the critical need for potential interleukins in the biological viability of blastocysts in terms of ensuing successful implantation and pregnancy outcome. This study provides a new, hitherto unexplored, role of IL-1 $\beta$ in peri-hatching blastocyst development in addition to its established role in blastocyst implantation. These conclusions have implications in our understanding of hatching biology and in the potential management of infertility in the human.

\section{Declaration of interest}

The authors declare that there is no conflict of interest that could be perceived as prejudicing the impartiality of the research reported.

\section{Funding}

This study was supported by grants from the Department of Science and Technology, New Delhi (Grant \#DST/EMR2016/003561) and partly by DBT-IISc Partnership Program (Grant \# 22-0307-0018-05-496).

\section{Author contribution statement}

Madhulika Pathak and Venkatappa Vani designed and performed embryo culture experiments. Madhulika Pathak collected samples, performed data acquisition, analyzed the data and wrote the draft of the manuscript. Polani B Seshagiri conceived and conceptualized the research program, designed experimental strategies and supervised all experiments. Surendra Sharma contributed to editing and drafting the manuscript for submission. All authors contributed to the interpretation of the results, preparation and finalization of the manuscript and they approved submission of the manuscript.

\section{Acknowledgements}

The authors thank Dr Surendra Sharma (Brown University, Providence, RI, USA) for providing/procuring IL-1 $\beta$ antibody for performing embryonic expression studies and for his interest in the study. The authors thank the bioimaging facility, Division of Biological Sciences, IISc, for providing all help in imaging immunostaining of embryos. The authors thank M S Padmavathi for her help during the preparation of the manuscript.

\section{References}

Abbondanzo SJ, Cullinan EB, McIntyre K, Labow MA \& Stewart CL 1996 Reproduction in mice lacking a functional type 1 IL-1 receptor. Endocrinology 137 3598-3601. (https://doi.org/10.1210/ endo.137.8.8754793)

Bulun SE 2017 Steroids, cytokines, and implantation. Endocrinology 158 1575-1576. (https://doi.org/10.1210/en.2017-00407)

Caluwaerts S, Pijnenborg R, Luyten C, Keith JC \& Van Assche FA 2002 Differential effects of IL-11 on rat blastocysts and decidua during the periimplantation period. American Journal of Reproductive Immunology 47 231-241. (https://doi.org/10.1034/j.1600-0897.2002.01070.x)

Chimote NM, Chimote NN, Nath NM \& Mehta BN 2013 Transfer of spontaneously hatching or hatched blastocyst yields better pregnancy rates than expanded blastocyst transfer. Journal of Human Reproductive Sciences 6 183-188. (https://doi.org/10.4103/0974-1208.121420)

Correia-Álvarez E, Gómez E, Martín D, Carrocera S, Pérez S, Otero J, Peynot N, Giraud-Delville C, Caamaño JN, Sandra O et al. 2015 Expression and localization of interleukin 1 beta and interleukin 1 receptor (type I) in the bovine endometrium and embryo. Journal of Reproductive Immunology 110 1-13. (https://doi.org/10.1016/j. jri.2015.03.006)

Gerwin N, Jia GQ, Kulbacki R \& Gutierrez-Ramos JC 1995 Interleukin gene expression in mouse preimplantation development. Developmental Immunology 4 169-179. (https://doi.org/10.1155/1995/26830) 
Ghannadi A, Kazerooni M, Jamalzadeh F, Amiri S, Rostami P \& Absalan F 2011 The effects of laser assisted hatching on pregnancy rates. Iranian Journal of Reproductive Medicine 9 95-98. (https://doi.org/10.1007/ s10103-017-2372-x)

Hammadeh ME, Fischer-Hammadeh C \& Ali KR 2011 Assisted hatching in assisted reproduction: a state of the art. Journal of Assisted Reproduction and Genetics 28 119-128. (https://doi.org/10.1007/s10815-010-94953)

Harlow GM \& Quinn P 1982 Development of preimplantation mouse embryos in vivo and in vitro. Australian Journal of Biological Sciences 35 187-193. (https://doi.org/10.1071/bi9820187)

Hogan B, Costantini F \& Lacy E 1986 Manipulating the Mouse Embryo, 4th ed., pp. 89-147, 250. Cold Spring Harbor Laboratory Press.

Huang Z, Liu J, Gao L, Zhuan Q, Luo Y, Zhu S, Lei K \& Fu X 2019 The impacts of laser zona thinning on hatching and implantation of vitrifiedwarmed mouse embryos. Lasers in Medical Science 34 939-945. (https:// doi.org/10.1007/s10103-018-2681-8)

Indalao IL, Sawabuchi T, Takahashi E \& Kido H 2017 IL-1 $\beta$ is a key cytokine that induces trypsin upregulation in the influenza virus-cytokine-trypsin cycle. Archives of Virology 162 201-211. (https://doi.org/10.1007/ s00705-016-3093-3)

Kita M, Tanaka K, Shinmura K, Tanaka Y, Liu Y \& Imanishi J 1994 Expression of cytokines and interferon-related genes in the mouse embryo. Comptes Rendus des Seances de la Societe de Biologie et de ses Filiales 188 593-600.

Kruessel JS, Huang HY, Wen Y, Kloodt AR, Bielfeld P \& Polan ML 1997 Different pattern of interleukin-1 beta-(IL-1 beta), interleukin-1 receptor antagonist- (IL-1RA) and interleukin-1 receptor type I- (IL$1 \mathrm{R} \mathrm{tl})$ mRNA-expression in single preimplantation mouse embryos at various developmental stages. Journal of Reproductive Immunology 34 103-120. (https://doi.org/10.1016/S0165-0378(97)00030-2)

Kruessel JS, Simón C, Rubio MC, Pape AR, Wen Y, Huang HY, Bielfeld P \& Polan ML 1998 Expression of interleukin-1 system mRNA in single blastomeres from human preimplantation embryos. Human Reproduction 13 2206-2211. (https://doi.org/10.1093/humrep/13.8.2206)

Lange-Consiglio A, Lazzari B, Pizzi F, Idda A, Cremonesi F \& Capra E 2020 Amniotic microvesicles impact hatching and pregnancy percentages of in vitro bovine embryos and blastocyst microRNA expression versus in vivo controls. Scientific Reports 10 501. (https://doi.org/10.1038/ s41598-019-57060-z)

Leonavicius K, Royer C, Preece C, Davies B, Biggins JS \& Srinivas S 2018 Mechanics of mouse blastocyst hatching revealed by a hydrogelbased micro deformation assay. PNAS 115 10375-10380. (https://doi. org/10.1073/pnas.1719930115)

Li D, Yang DL, An J, Jiao J, Zhou YM, Wu QJ \& Wang XX 2016 Effect of assisted hatching on pregnancy outcomes: a systematic review and meta-analysis of randomized controlled trials. Scientific Reports 6 31228. (https://doi.org/10.1038/srep31228)

Lin SP, Lee RK \& Tsai YJ 2001 In vivo hatching phenomenon of mouse blastocysts during implantation. Journal of Assisted Reproduction and Genetics 18 341-345. (https://doi.org/10.1023/A:1016640923269)

Lin CC, Kuo CT, Cheng CY, Wu CY, Lee CW, Hsieh HL, Lee IT \& Yang CM 2009 IL-1 beta promotes A549 cell migration via MAPKs/AP-1- and NF-kappaB-dependent matrix metalloproteinase-9 expression. Cellular Signalling 21 1652-1662. (https://doi.org/10.1016/j.cellsig.2009.07.002)

Lindroos PM, Rice AB, Wang YZ \& Bonner JC 1998 Role of nuclear factor-kappa $B$ and mitogen-activated protein kinase signaling pathways in IL-1 beta-mediated induction of alpha-PDGF receptor expression in rat pulmonary myofibroblasts. Journal of Immunology $1613464-3468$.

Lu X, Liu Y, Cao X, Liu SY \& Dong X 2019 Laser-assisted hatching and clinical outcomes in frozen-thawed cleavage-embryo transfers of patients with previous repeated failure. Lasers in Medical Science 34 1137-1145. (https://doi.org/10.1007/s10103-018-02702-3)

Mishra A \& Seshagiri PB 1998 Successful development in vitro of hamster 8-cell embryos to 'zona-escaped' and attached blastocysts: assessment of quality and trophoblast outgrowth. Reproduction, Fertility, and Development 10 413-420. (https://doi.org/10.1071/rd98100)

Murphy SP, Fast LD, Hanna NN \& Sharma S 2005 Uterine NK cells mediate inflammation-induced fetal demise in IL-10-null mice. Journal of Immunology 175 4084-4090. (https://doi.org/10.4049/ jimmunol.175.6.4084)
Nakasato M, Nagata M \& Aoki F 2004 Expression of cytokine receptors in pre-implantation mouse embryos. Journal of Mammalian Ova Research 21 128-133. (https://doi.org/10.1274/jmor.21.128)

O'Sullivan CM, Rancourt SL, Liu SY \& Rancourt DE 2001 A novel murine tryptase involved in blastocyst hatching and outgrowth. Reproduction 122 61-71. (https://doi.org/10.1530/rep.0.1220061)

O'Sullivan CM, Liu SY, Karpinka JB \& Rancourt DE 2002 Embryonic hatching enzyme strypsin/ISP1 is expressed with ISP2 in endometrial glands during implantation. Molecular Reproduction and Development 62 328-334. (https://doi.org/10.1002/mrd.10142)

Pan X, Wang X, Wang X, Sun Z, Zhang X, Liang X, Li Z \& Dou Z 2015 Nitric oxide regulates blastocyst hatching in mice. International Journal of Clinical and Experimental Medicine 8 6994-7001.

Paula-Lopes FF, de Moraes AAS, Edwards JL, Justice JE \& Hansen PJ 1998 Regulation of preimplantation development of bovine embryos by interleukin-1 $\beta$. Biology of Reproduction 59 1406-1412. (https://doi. org/10.1095/biolreprod59.6.1406)

Perona RM \& Wassarman PM 1986 Mouse blastocysts hatch in vitro by using a trypsin-like proteinase associated with cells of mural trophectoderm. Developmental Biology 114 42-52. (https://doi.org/10.1016/00121606(86)90382-9)

Raheem KA 2018 Cytokines, growth factors and macromolecules as mediators of implantation in mammalian species. International Journal of Veterinary Science and Medicine 6 S6-S14. (https://doi.org/10.1016/j. ijvsm.2017.12.001)

Robertson SA, Sjoblom C, Jasper MJ, Norman RJ \& Seamark RF 2001 Granulocyte-macrophage colony-stimulating factor promotes glucose transport and blastomere viability in murine preimplantation embryos. Biology of Reproduction 64 1206-1215. (https://doi.org/10.1095/ biolreprod64.4.1206)

Robertson SA, China PY, Femiaa JG \& Browna HM 2018 Embryotoxic cytokines-potential roles in embryo loss and fetal programming. Journal of Reproductive Immunology 125 80-88. (https://doi.org/10.1016/j. jri.2017.12.003)

Roth TL, Swanson WF \& Wildt DE 1994 Developmental competence of domestic cat embryos fertilized in vivo versus in vitro. Biology of Reproduction 51 441-451. (https://doi.org/10.1095/biolreprod51.3.441)

Salama KM, Alloush MK \& Al Hussini RM 2020 Are the cytokines TNF alpha and IL 1beta early predictors of embryo implantation? Cross sectional study. Journal of Reproductive Immunology 137102618. (https://doi.org/10.1016/j.jri.2019.102618)

Sathananthan H, Menezes J \& Gunasheela S 2003 Mechanics of human blastocyst hatching in vitro. Reproductive Biomedicine Online 7 228-234. (https://doi.org/10.1016/s1472-6483(10)61757-9)

Sawada H, Yamazaki K \& Hoshi M 1990 Trypsin-like hatching protease from mouse embryos: evidence for the presence in culture medium and its enzymatic properties. Journal of Experimental Zoology 254 83-87. (https://doi.org/10.1002/jez.1402540112)

Schmitz T, Leroy MJ, Dallot E, Breuiller-Fouche M, Ferre F \& Cabrol D 2003 Interleukin-1 $\beta$ induces glycosaminoglycan synthesis via the prostaglandin E2 pathway in cultured human cervical fibroblasts. Molecular Human Reproduction 9 1-8. (https://doi.org/10.1093/molehr/ gag007)

Schneider EG, Armant DR, Kupper TS \& Polan ML 1989 Absence of a direct effect of recombinant interleukins and cultured peritoneal macrophages on early embryonic development in the mouse. Biology of Reproduction 40 825-833. (https://doi.org/10.1095/biolreprod40.4.825)

Sen Roy S \& Seshagiri PB 2013 Expression and function of cyclooxygenase-2 is necessary for hamster blastocyst hatching. Molecular Human Reproduction 19 838-851. (https://doi.org/10.1093/molehr/gat063)

Sen Roy S \& Seshagiri PB 2016 The NF-кB signaling system is required for blastocyst hatching in the golden hamster: mediated by the expression of hatching-promoting cathepsins. Journal of Reproductive Health and Medicine 2 74-82. (https://doi.org/10.1016/j.jrhm.2016.03.002)

Sequeira K, Espejel-Nunez A, Vega-Hernandez E, Molina-Hernandez A \& Grether-Gonzalez P 2015 An increase in IL-1 $\beta$ concentrations in embryo culture-conditioned media obtained by in vitro fertilization on day 3 is related to successful implantation. Journal of Assisted Reproduction and Genetics 32 1623-1627. (https://doi.org/10.1007/s10815-015-0573-4)

Seshagiri PB, Sen Roy S, Sireesha G \& Rao RP 2009 Cellular and molecular regulation of mammalian blastocyst hatching. Journal of Reproductive Immunology 83 79-84. (https://doi.org/10.1016/j.jri.2009.06.264) 
Seshagiri PB, Vani V \& Madhulika P 2016 Cytokines and blastocyst hatching. American Journal of Reproductive Immunology 75 208-217. (https://doi.org/10.1111/aji.12464)

Seymour JF, Lieschke GJ, Grail D, Quilici C, Hodgson G \& Dunn AR 1997 Mice lacking both granulocyte colony-stimulating factor (CSF) and granulocyte-macrophage CSF have impaired reproductive capacity, perturbed neonatal granulopoiesis, lung disease, amyloidosis, and reduced long-term survival. Blood 90 3037-3049. (https://doi. org/10.1182/blood.V90.8.3037)

Shafei RA, Syrkasheva AG, Romanov AY, Makarova NP, Dolgushina NV \& Semenova ML 2017 Blastocyst hatching in humans. Russian Journal of Developmental Biology 48 5-15. (https://doi.org/10.1134/ S1062360417010106)

Sharma N, Liu S, Tang L, Irwin J, Meng G \& Rancourt DE 2006 Implantation serine proteinases heterodimerize and are critical in hatching and implantation. BMC Developmental Biology 6 61. (https:// doi.org/10.1186/1471-213X-6-61)

Simón C, Valbuena D, Krüssel J, Bernal A, Murphy CR, Shaw T, Pellicer A \& Polan ML 1998 Interleukin-1 receptor antagonist prevents embryonic implantation by a direct effect on the endometrial epithelium. Fertility and Sterility 70 896-906. (https://doi.org/10.1016/S0015-0282(98)00275-1)

Singh M, Chaudhry P \& Asselin E 2011 Bridging endometrial receptivity and implantation: network of hormones, cytokines, and growth factors. Journal of Endocrinology 210 5-14. (https://doi.org/10.1530/ JOE-10-0461)

Sireesha GV, Mason RW, Hassanein M, Tonack S, Navarrete Santos A, Fischer B \& Seshagiri PB 2008 Role of cathepsins in blastocyst hatching in the golden hamster. Molecular Human Reproduction 14 337-346. (https://doi.org/10.1093/molehr/gan026)

Stewart CL \& Cullinan EB 1997 Preimplantation development of the mammalian embryo and its regulation by growth factors. Developmental Genetics $21 \quad 91-101 . \quad$ (https://doi.org/10.1002/(SICl)15206408(1997)21:1<91::AID-DVG11>3.0.CO;2-D)

Stewart CL, Kaspar P, Brunet LJ, Bhatt H, Gadi I, Köntgen F \& Abbondanzo SJ 1992 Blastocyst implantation depends on maternal expression of leukaemia inhibitory factor. Nature 359 76-79. (https:// doi.org/10.1038/359076a0)

Stokes PJ, Abeydeera LR \& Leese HJ 2005 Development of porcine embryos in vivo and in vitro; evidence for embryo 'cross talk' in vitro. Developmental Biology 284 62-71. (https://doi.org/10.1016/j. ydbio.2005.05.001)

Taft RA 2008 Virtues and limitations of the preimplantation mouse embryo as a model system. Theriogenology 69 10-16. (https://doi.org/10.1016/j. theriogenology.2007.09.032)

Tartakovsky B \& Ben-Yair E 1991 Cytokines modulate preimplantation development and pregnancy. Developmental Biology 146 345-352. (https://doi.org/10.1016/0012-1606(91)90236-V)

Uri-Belapolsky S, Shaish A, Eliyahu E, Grossman H, Levi M, Chuderland D, Ninio-Many L, Hasky N, Shashar D, Almog T et al. 2014 Interleukin-1 deficiency prolongs ovarian lifespan in mice. PNAS 111 12492-12497. (https://doi.org/10.1073/pnas.1323955111)

von Wolff M, Thaler CJ, Strowitzki T, Broome J, Stolz W \& Tabibzadeh S 2000 Regulated expression of cytokines in human endometrium throughout the menstrual cycle: dysregulation in habitual abortion. Molecular Human Reproduction 6 627-634. (https://doi.org/10.1093/ molehr/6.7.627)

Weber A, Wasiliew P \& Kracht M 2010 Interleukin-1 (IL-1) pathway. Science Signaling $3 \mathrm{~cm} 1$. (https://doi.org/10.1126/scisignal.3105cm1)

Zhan S, Cao S, Du H, Sun Y, Li L, Ding C, Zheng H \& Huang J 2018 Parental genetic material and oxygen concentration affect hatch dynamics of mouse embryo in vitro. Reproductive Biology and Endocrinology 1639. (https://doi.org/10.1186/s12958-018-0356-8)

Received 5 July 2020

First decision 25 August 2020

Revised manuscript received 19 November 2020

Accepted 24 November 2020 